\title{
Complex Composite Odontoma with Characteristic Histology
}

\author{
Sujatha Govindrajan, ${ }^{1}$ J. Muruganandhan, ${ }^{1}$ Shaik Shamsudeen, ${ }^{1}$ Nalin Kumar, ${ }^{1}$ \\ M. Ramasamy, ${ }^{2}$ and Srinivasa Prasad ${ }^{3}$ \\ ${ }^{1}$ Department of Oral and Maxillofacial Pathology, Sri Venkateswara Dental College and Hospital, Thalambur, Chennai 603103, India \\ ${ }^{2}$ Department of Orthodontics, Sri Venkateswara Dental College and Hospital, Thalambur, Chennai 603103, India \\ ${ }^{3}$ Department of Oral and Maxillofacial Surgery, Sri Venkateswara Dental College and Hospital, Thalambur, Chennai 603103, India
}

Correspondence should be addressed to J. Muruganandhan; drmurugan@outlook.com

Received 23 April 2013; Accepted 28 May 2013

Academic Editors: I. El-Hakim and S. R. Watt-Smith

Copyright (c) 2013 Sujatha Govindrajan et al. This is an open access article distributed under the Creative Commons Attribution License, which permits unrestricted use, distribution, and reproduction in any medium, provided the original work is properly cited.

Odontomas are the most commonly occurring odontogenic tumors, which are considered by many to be hamartomas rather than neoplasms. These clinically asymptomatic tumors are classified into complex and compound odontomas. They are usually discovered in radiographs and rarely cause bony expansion or infection. This paper discusses a case report of a complex odontoma exhibiting all the structural features and defects of enamel, dentine, and cementum in succession, with an overview on its etiology.

\section{Introduction}

Hamartomas of tooth forming tissues are termed as odontoma. They are the most common tumor of epithelial and mesenchymal origin and account for $22 \%$ of all odontogenic tumors [1]. This nonaggressive benign tumor contains enamel, dentin, cementum, and pulp either arranged in an orderly manner resembling a rudimentary tooth called compound odontoma or arranged in a haphazard manner called complex odontoma. Complex odontoma is less common when compared to the compound, and they present in ratio of $1: 2$ [2]. Odontomas rarely erupt in the oral cavity. We present a case of a partially erupted odontoma in the right third molar region.

\section{Case Report}

A 28-year-old male patient reported to a private clinic with a complaint of pain in the right lower posterior tooth region for about one week. On intraoral examination, a partially erupted tooth-like structure was seen. The pain was intermittent and was aggravated on chewing. Radiographic investigation revealed the presence of near-spherical opaque mass resembling calcified tissue measuring about $2 \mathrm{~cm}$ in diameter. The radiopaque mass with a density greater than bone and equal or greater than that of tooth was surrounded by a radiolucent rim in all areas except the erupted portion distal to normally erupted second molar (Figure 1).

Removal of the mass was planned under local anaesthesia. Mucoperiosteal flap was raised distal to 47 , and the calcified mass was removed. The spherical mass was about $2 \mathrm{~cm}$ in diameter with small irregular areas of indentations. The inferior side of the mass showed a hollow invagination giving the appearance of a small cup (Figure 2). The specimen was sent for histopathological examination. A diagnosis of complex odontoma was made clinically.

Ground sections were done on the dissected halves of the hard tissue mass. The ground section showed areas of enamel, dentine, and cementum in succession (Figure 3 ). The enamel showed uneven thickness and undulating surface. Hypocalcified areas like lamellae, spindles, tufts, and incremental lines were seen (Figures 4 and 5). Some areas showed irregular rod patterns and gnarled enamel (Figure 6).

The dentinoenamel junction was regular and scalloped in some areas. The underlying dentine showed "S" shaped dentinal tubules. Primary and secondary dentine types were observed with clearly visible incremental lines (Figure 7). Hypocalcified areas like interglobular dentine and Tomes' granular layer were also observed (Figures 8 and 9). Dead tracts were also seen (Figure 9). Next to the dentine there 


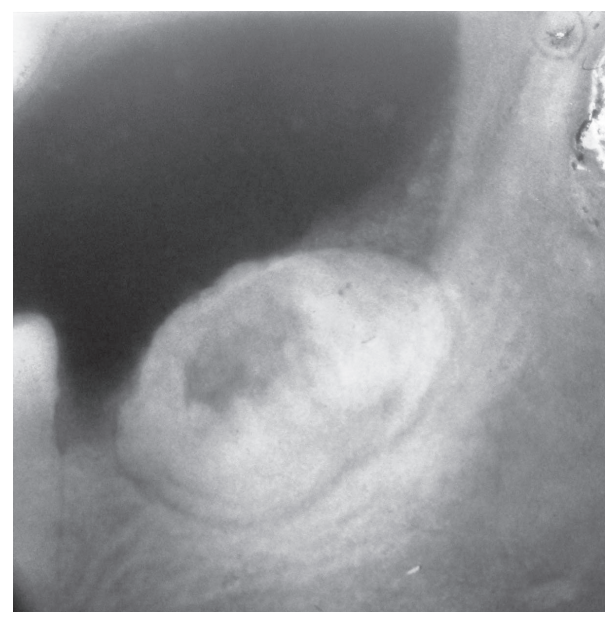

FIGURE 1: Radiographic image of the odontoma.

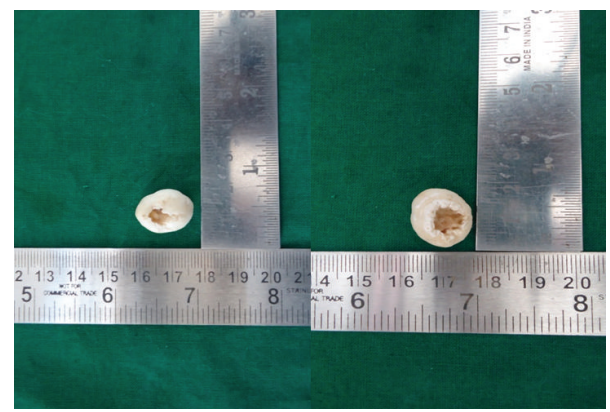

FIgURE 2: Superior and inferior surface of odontoma.

was a layer of cementum of varying thickness. Both types of cementum were observed. The cellular cementum was more prominent with numerous cementocytes. Each cementocyte had about 8-10 canaliculi, which are branching and oriented away from the dentinal surface (Figure 10).

\section{Discussion}

Paul Braco in 1867 was the first to coin the term odontoma and defined the term as tumors formed by the overgrowth or transition of complete dental tissue [3]. It is a growth in which both the epithelial and mesenchymal cells exhibit complete differentiation resulting in formation of enamel and dentin by the functional ameloblasts and odontoblasts. These odontogenic cells are usually disorganized, and the enamel, dentine, and pulpal tissue are laid down in an abnormal pattern [4]. Our case represented the presence of functional ameloblast, odontoblast, and cementoblast by formation of these normal hard tissue structures. WHO has classified four tumors which arise from mixed tissue origin giving normal enamel and dentine formation, odontoma being the most common of them [5].

According to WHO, this lesion is "a malformation in which all the dental tissues are represented, individual tissues being mainly formed but occurring in more or less disorderly

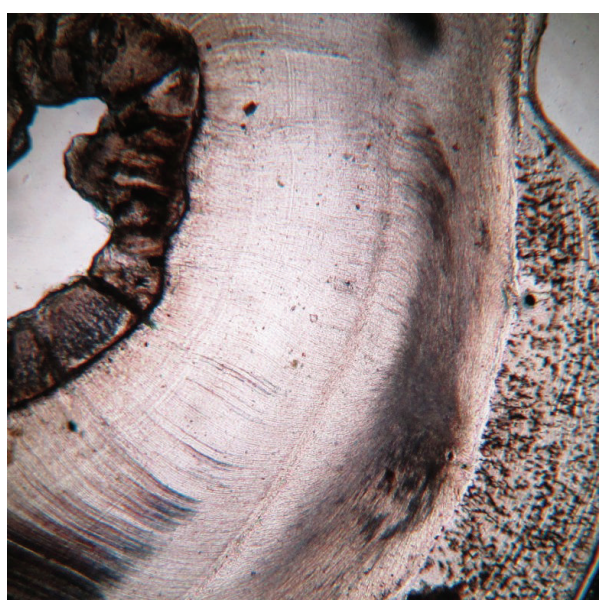

FIGURE 3: Enamel, dentine and cementum in succession (photomicrograph, ground section $10 \mathrm{x}$ ).

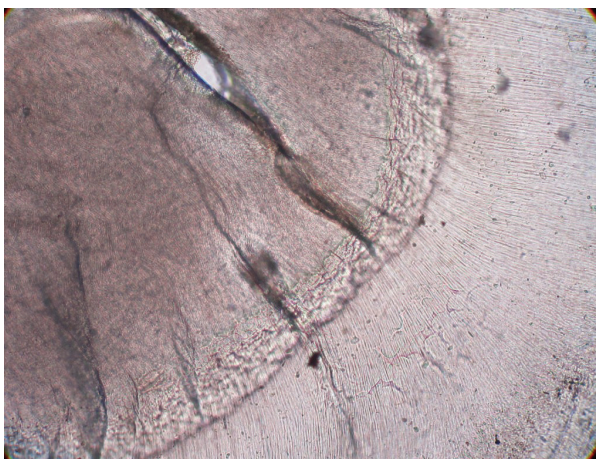

FIgure 4: Presence of lamellae, spindles and tufts (photomicrograph, ground section 10x).

pattern." When the calcified tissues are simply arranged in an irregular mass bearing no morphological similarity to rudimentary teeth, they are termed complex odontoma. A compound odontoma comprises calcified structures arranged in an orderly pattern that result in many teeth-like structures, but without morphological resemblance to normal tooth [6]. Our case presented as an irregular mass and was classified as a complex odontoma.

The etiology of odontoma is not clear, and various causes like local trauma, infection, hereditary anomalies like Gardner's syndrome, Hermann's syndrome, odontoblastic hyperactivity, and alteration in genetic components responsible for tooth development are also considered [7]. Hitchin suggested that odontomas are inherited (through a mutant gene) due to interference, possibly postnatal, with genetic control of tooth development [8]. Experimental studies in rats suggested the role of trauma in formation of odontomas [9].

Sources of cells for odontomas could be mature ameloblasts, cell rests of Serres, or extraneous odontogenic epithelial cells $[1,10-12]$. These cells can be stimulated by either environmental or genetic factors. Genetic factors could be either due to inheritance of abnormal genes or mutation of the responsible genes and interference in the mechanism of genes controlling tooth formation [7]. 


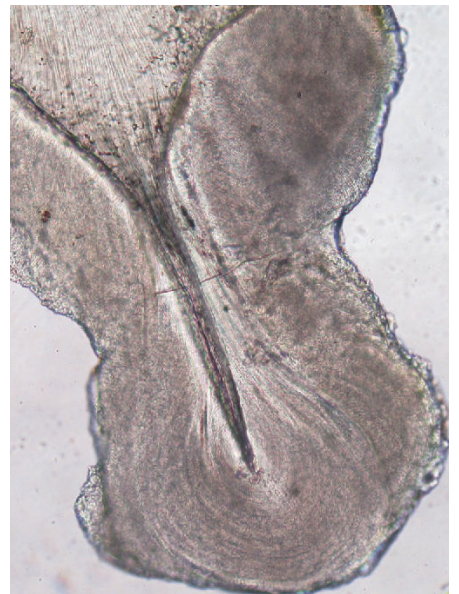

Figure 5: Incremental lines of enamel (photomicrograph, ground section 10x).

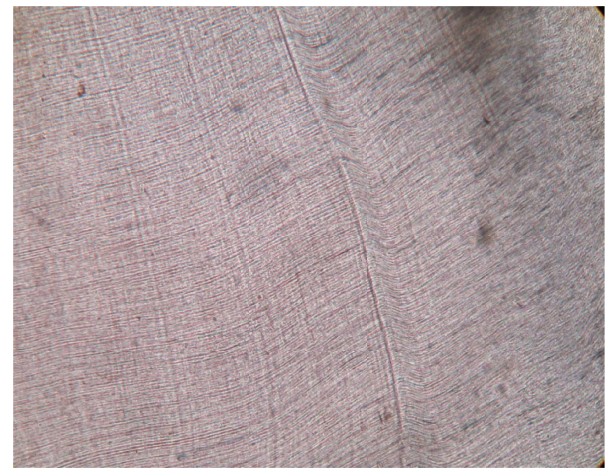

Figure 6: Dentinal tubules with incremental lines (photomicrograph, ground section 10x).

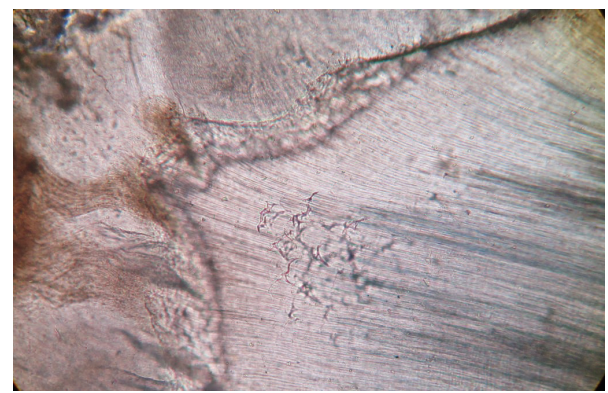

FIGURE 7: Interglobular dentine (photomicrograph, ground section $10 \mathrm{x})$.

Environmental factors like trauma, growth pressure, and infection may play a role in the pathogenesis of odontoma. A vertically directed force in the form of trauma which is directed to the permanent tooth bud through the deciduous tooth can lead to morphological changes in the permanent tooth bud leading to formation of odontomas [13]. Studies by Glasstone (1952) and Rushton (1957) have supported the role of trauma in the development of odontoma [8]. Levy states that the stage of development during which the trauma

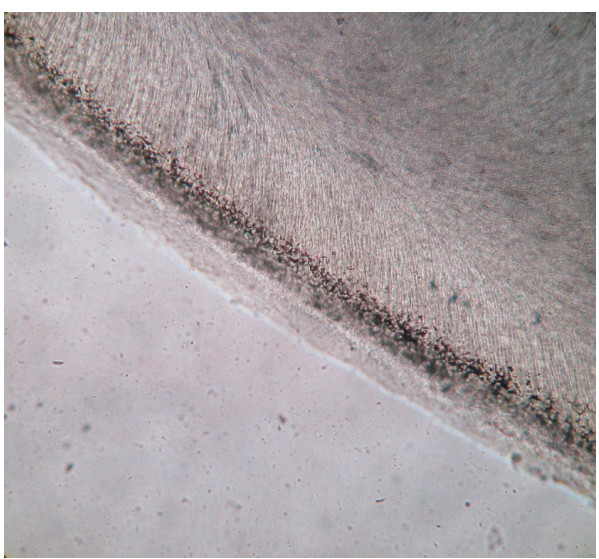

FIgURE 8: Tomes granular layer (photomicrograph, ground section 10x).

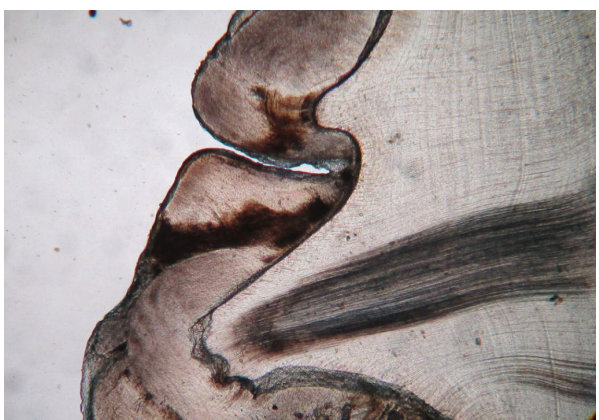

FIGURE 9: Dead tracts and gnarled enamel (photomicrograph, ground section 10x).

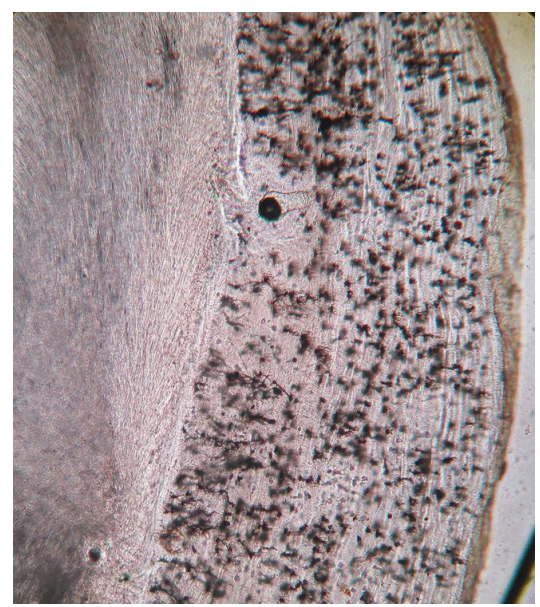

FIGURE 10: Cemetocytes with canaliculi (photomicrograph, ground section $10 \mathrm{x})$.

has occurred determines the development of hypoplastic teeth, odontomas, and supernumerary tooth [9]. Presence of odontoma in sites other than tooth bearing regions suggests that trauma could have possibly displaced the developing tooth germ leading to its malformation [14].

Growth pressure due to inadequate space is been quoted as the etiology in some odontomas. This theory by Hitchin 
states that abnormal pressure from the deciduous roots over the developing tooth germ could lead to the formation of odontomas $[8,15,16]$. Infections can cause the division of tooth germ or interfere with tooth development [7].

Odontomas were discovered at any age but the most prevalent age of detection was the second decade of life with a slight predilection for occurrence in males when compared to females [17]. Compound odontomas are more common in the anterior segment of the jaws (61\%), and complex odontomas are more common in the posterior segment (59\%), with higher occurrence in the right than in the left side [4]. Compound odontomas are commonly seen in the incisorcuspid region of maxilla and complex type in the premolarmolar region of mandible [18]. In our case, the patient was a middle aged male patient with the complex odontoma occurring in the right posterior segment of the mandible.

Odontomas are clinically asymptomatic, although occasionally retention of deciduous teeth, noneruption, swelling, pain, tooth displacement, cortical bone expansion, and infection may be noted [19]. Alterations to neighboring teeth such as malpositioning, devitalisation, malformation, aplasia, and retained teeth were observed in $70 \%$ of the cases [20]. Odontomas are classified as intraosseous when seen totally embedded in the bone with or without signs of eruption and extraosseous when present in the soft tissues over the tooth bearing bone [21].

Eruption of odontomas is different from a normal tooth as there is lack of periodontal ligament. As there is no root formation, the increasing size of the odontoma leads to sequestration of the overlying bone by causing pressure and eventually occlusal movement and eruption [22]. Bone remodeling is considered as the other possible factor in initiating eruption. Cellular activity in reduced enamel epithelium and dental follicles is required for eruption. Epidermal growth factor $\beta$ [EGF- $\beta$ ] and transforming growth factor [TGF] are expressed by signals from reduced enamel epithelium, helping in production of colony-stimulating factor by the follicular cells, recruiting osteoclasts to the follicle. Proteases secreted by reduced enamel epithelium also help in breakdown of follicle and produce a path of least resistance [23].

Diagnosis of odontomas is usually by radiographs. A routine intraoral radiograph helps in diagnosing the presence of odontoma and the classification is usually by visualization. A compound odontoma, in a radiograph shows well-organized malformed tooth or tooth-like structures in a radiolucent follicle-like space whereas the complex type shows irregularly shaped radiopacity surrounded by a radiolucent rim. In cases where there are numerous tooth-like structures in a compound odontoma, differentiating the two becomes difficult [7]. If both visual and radiographic images fail to give a definite diagnosis as in some cases, other procedures like histologic examination are used. In our case, though we established a diagnosis of complex odontoma through radiographic and visual examination, we decided to see the histological features through ground section.

Ground section usually reveals the presence of all hard tissues in succession representing enamel, dentine, and cementum. Hypocalcified areas of both enamel and dentine are seen. In our case, the microscopy showed remarkable features that make for interesting discussion. Treatment of odontomas is usually by conservative surgical removal and preservation of impacted or embedded tooth if present.

\section{Conclusion}

Odontomas are common odontogenic tumors, which are usually asymptomatic and are diagnosed by routine radiographs. Etiology of this tumor is not clear, and López-Areal in his study has supported the role of injury during childhood for formation of odontomas [24]. In our case, though the patient did not give a clear history of childhood injury, presence of the normal structures in an orderly pattern gives us an opinion that some mild interference during formation of third molar has occurred.

\section{Acknowledgment}

The authors thank their lab technician Mrs. M. Elavarasi for helping them prepare this slide.

\section{References}

[1] S. N. Bhaskar, "Odontogenic tumors of jaws," in Synopsis of Oral Pathology, pp. 292-2303, Mosby, 7th edition, 1986.

[2] D. M. Cohen and I. Bhattacharyya, "Ameloblastic fibroma, ameloblastic fibro-odontoma, and odontoma," Oral and Maxillofacial Surgery Clinics of North America, vol. 16, no. 3, pp. 375384, 2004.

[3] E. Sprawson, “Odontomas," British Dental Journal, vol. 62, pp. 177-201, 1937.

[4] G. W. Shafer, M. K. Hine, and B. M. Levy, Eds., A Text Book of Oral Pathology, WB Saunders, Philadelphia, Pa, USA, 4th edition, 1983.

[5] J. J. Pindborg, I. R. H. Kramer, and H. Torloni, "Histologic typing of odontogenic tumors, jaw cysts and allied lesions," in International Histological Classification of Jaw Tumors, vol. 5, pp. 29-230, World Health Organisation, Geneva, Switzerland, 1970.

[6] I. R. H. Kramer, J. J. Pindborg, and M. Shear, Histological Typing of Odontogenic Tumors, WHO International Histological Classification of Tumors, Springer, Berlin, Germany, 2nd edition, 1992.

[7] V. Satish, M. C. Prabhudevi, and R. Sharma, "Odontoma: a brief overview," International Journal of Clinical Pediatric Dentistry, vol. 4, pp. 177-185, 2011.

[8] A. D. Hitchin, "The etiology of the calcified composite odontomas," British Dental Journal, vol. 130, pp. 475-482, 1971.

[9] B. A. Levy, "Effects of experimental trauma on developing first molar teeth in rats," Journal of Dental Research, vol. 47, no. 2, pp. 323-327, 1968.

[10] E. F. Torreti and R. Carrel, "Compound odontoma in a twelveyear-old girl," ASDC Journal of Dentistry for Children, vol. 50, no. 5, pp. 376-378, 1983.

[11] O. Fijerskov, "Odontogenesis," in Histology of the Human Tooth, I. A. Mjor and O. Fijerskov, Eds., pp. 21-31, Munksgaard, Copenhagen, Denmark, 1st edition, 1979.

[12] R. M. Smith, J. E. Tuner, and A. L. Ribbins, Atlas of Oral Pathology, CV Mosby, St Louis, Mo, USA, 1981. 
[13] J. O. Andreason, "Injuries to developing teeth," in Textbook and Color Atlas of Traumatic Injuries to Teeth, J. O. Andreason and F. M. Andreason, Eds., pp. 457-494, Mosby, Copenhagen, Denmark, 3rd edition, 1993.

[14] A. Shteyer, S. Taicher, and Y. Marmary, "Odontoma in the subcondylar region," British Journal of Oral Surgery, vol. 17, no. 2, pp. 161-165, 1979.

[15] P. Gurdal and T. Seckin, “Odontomas," Quintessence International, vol. 4, article 32, 2001.

[16] A. D. Hitchin and W. D. Mchugh, "Three coronal invaginations in a dilated composite odontome," British Dental Journal, vol. 97, pp. 90-92, 1954.

[17] M. Vengal, H. Arora, S. Ghosh, and K. M. Pai, "Large erupting complex odontoma: a case report," Journal of the Canadian Dental Association, vol. 73, no. 2, pp. 169-172, 2007.

[18] O. P. Kharbanda, C. S. Sambi, and K. Renu, "Odontoma: a case report," Journal of the Indian Dental Association, vol. 58, pp. 269-271, 1986.

[19] M. S. Tuzum, "Orofacial pain associated with an infected complex odontoma-case report," Australian Dental Journal, vol. 3, pp. 352-354, 1990.

[20] M. Kaneko, M. Fukuda, T. Sano, T. Ohnishi, and Y. Hosokawa, "Microradiographic and microscopic investigation of a rare case of complex odontoma," Oral Surgery, Oral Medicine, Oral Pathology, Oral Radiology, and Endodontics, vol. 86, no. 1, pp. 131-134, 1998.

[21] L. Junquera, J. C. de Vicente, P. Roig, S. Olay, and O. RodríguezRecio, "Intraosseus odontoma erupted into the oral cavity: an unusual pathology," Medicina Oral, Patologia Oral y Cirugia Bucal, vol. 10, no. 3, pp. 248-251, 2005.

[22] A. R. Ten Cate and A. Nanci, "Physiologic tooth movements: eruption and shedding," in Ten Cate's Oral Histology: Development, Structure and Function, A. Nanci, Ed., pp. 275-298, Mosby, St. Louis, Mo, USA, 2003.

[23] P. B. Sood, B. Patil, S. Godhi, and D. C. Shetty, "Multiple supernumerary teeth and odontoma in the maxilla: a case report," Contemporary Clinical Dentistry, vol. 1, pp. 45-46, 2010.

[24] L. López-Areal, F. Silvestre Donat, and J. Gil Lozano, "Compound odontoma erupting in the mouth: 4-year follow-up of a clinical case," Journal of Oral Pathology and Medicine, vol. 21, no. 6, pp. 285-288, 1992. 


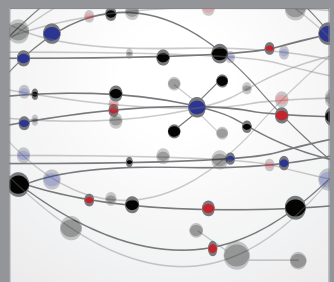

The Scientific World Journal
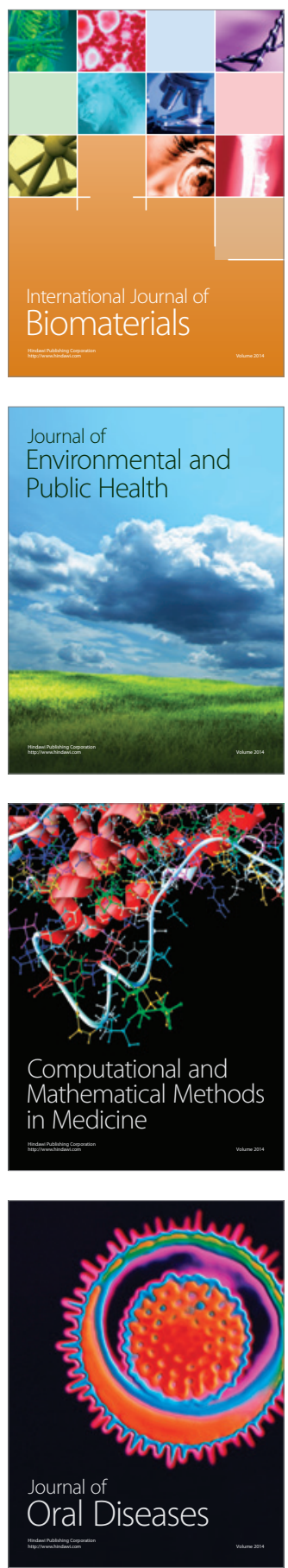
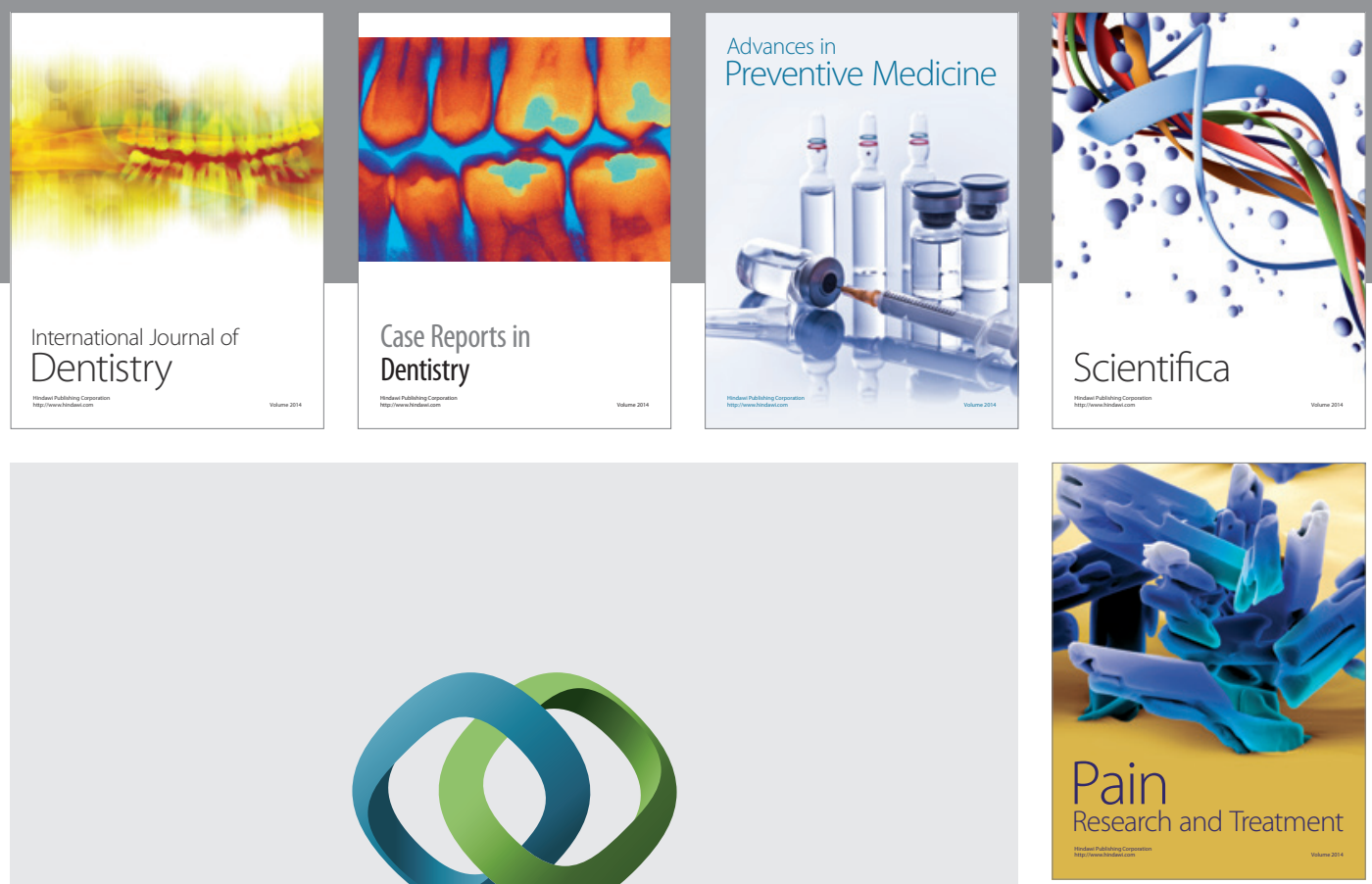

\section{Hindawi}

Submit your manuscripts at

http://www.hindawi.com
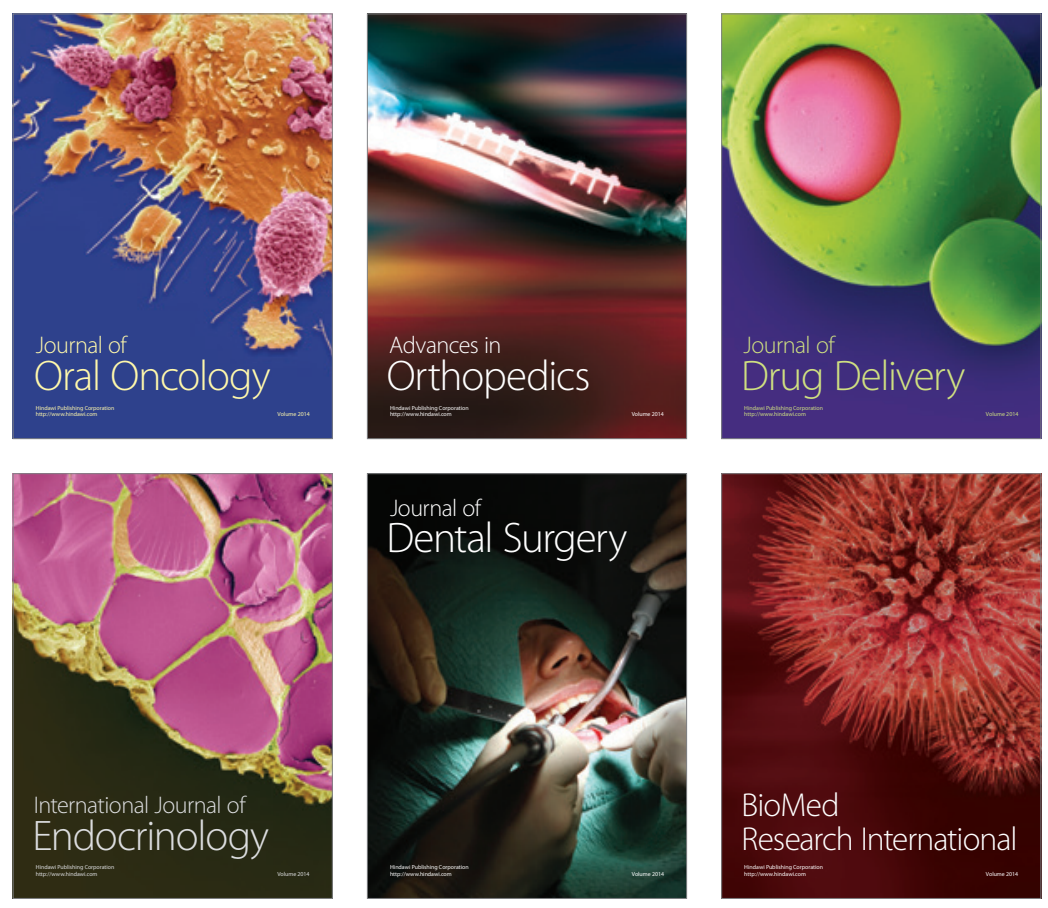

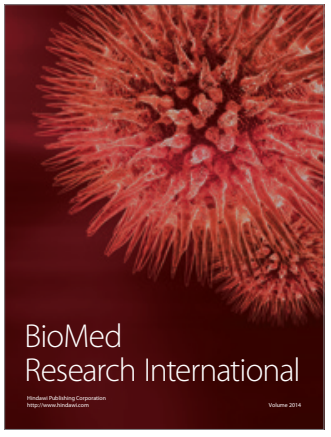

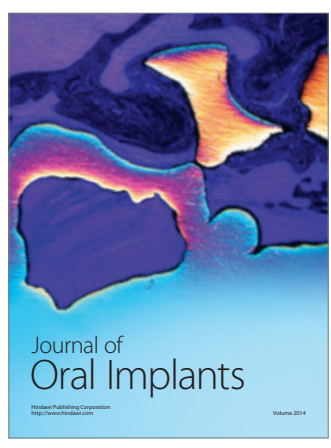
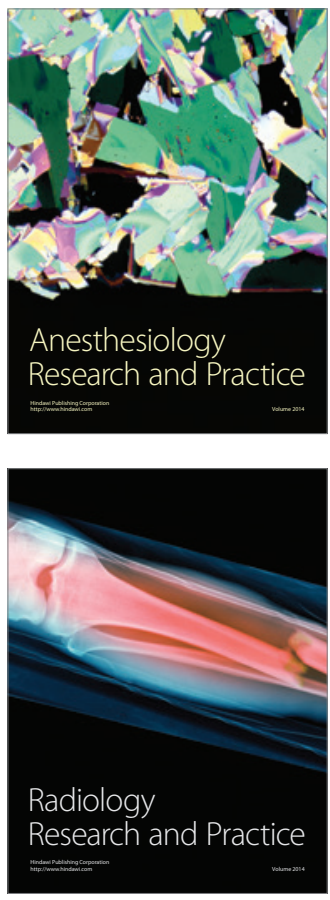